\title{
THE PLACE OF THE SCIENTIST IN CIVIL DEFENCE
}

$\mathrm{O}^{\prime}$ $\mathrm{N}$ the evening of October 16 , the London and South-Eastern Counties Section of the Royal Institute of Chemistry, the London and Home Counties Branch of the Institute of Physics and the Institute of Biology met in the City of London School to discuss the place of the scientist in civil defence. Speaking from the chair, Dr. C. W. Herd, chairman of the local section of the Royal Institute of Chemistry, said the meeting had been arranged to enable members to state their vjews on the employment of scientists in civil defence, and, so that they might hear something from the official angle, he was glad to introduce the Director-General of Training and the Scientific Adviser to the Home Office and also the honorary scientific advisers from the London Civil Defence Region.

In outlining points which were causing anxiety, Dr. Herd said he would be expressing personal views ; but these were based on many discussions with professional colleagues, so he thought they would be typical of the opinions of many members present. During the Second World War, there was a good deal of dissatisfaction over the status of gas jdentification officers in relation to other branches of civil defence. To-day he felt that official recognition of the professional standing of chemists, physicists and biologists recruited for technical reconnaissance was inadequate to enable the services of these officers to be utilized effectively. This resulted in a sense of frustration among the officers concerned and might even prevent some from offering their services. Senior technical reconnaissance officers should, in their special field, be recognized as competent advisers to civil defence controllers. At present, to be quite frank, he said, professional men lack confidence in the scientific side of civil defence at local-authority level, and this confidence must be built up if the scheme is to be a success.

After referring to other points which on present evidence seem unsatisfactory, Dr. Herd said he thought the duty of the technical reconnaissance officer should be first to the public, to inspire confidence and maintain morale; secondly, to the civil defence controller to advise on scientific and technical matters ; thirdly, to direct technical reconnaissance; and, finally, to collect scientific and technical information for transmission to regional advisers. He suggested that a senior technical reconnaissance officer should be free to gather around him all scientists in his district and to give them technical information and training, so that there would be a pool of trained men available to deal with any emergency in addition to those officially recruited to the headquarters establishment. Potential recruits should now be reassured regarding their status in the corps and their method of recruitment, with full information of the nature of their duties and the amount of training they would have to undertake. Regarding training, they should not be expected to attend very elementary lectures on technical subjects. Once in the corps, interest should be maintained through periodic meetings officially organized to keep them up to date in their subjects. Such meetings should not be left to the initiative of the officers themselves as happened during 1939-45.

Prof. W. V. Mayneord, one of the London regional scientific advisers, said that scientists ought to remember they are all primarily citizens, so that many of their duties are the same as other members of the community, even though the highly technical nature of modern warfare throws a special responsibility upon them. The contribution a person could make to civil defence depends upon his general training, and a physicist's first approach to the problem should be in the direction of quantitative studies of the effects of weapons in different circum stances. Such work could help the scientists officially employed on this type of research. The first thing to remember about the atomic bomb is the fear of the unknown that such a weapon creates. The trained scientist should therefore make himself as well informed as possible on all aspects of the subject, so that he might win the confidence of the public and do valuable work by allaying unwarranted fears.

Prof. Mayneord then dealt with the technical aspects of an atomic explosion, pointing out that radiation effects, though of great scientific interest, are likely to be only of secondary importance in causing casualties. Existing knowledge could be used to assess the relative values of different materials in building structures as protection against the penetration of radiation. Similarly, knowledge of the dose required to produce specific effects could be used to determine the circumstances in which the civil defence services could work in complete safety or when, in emergency, a calculated risk might be deliberately accepted. The scientist could be of value in the training of non-technical people, especially in designing the form which such instruction should take, as this is most important. To sum up, the scientist in civil defence should make himself a competent adviser in whom his controller will have full confidence, and in reconnaissance work the aim should be accurate observation and reporting of significant facts followed by informed interpretation of this information, so that it could be quickly and effectively used in dealing with the tactical situation.

Prof. H. N. Rydon who, until his recent appointment to Manchester, was also one of the scientific advisers in the London Region, then discussed the nature and magnitude of the problems resulting from the use of biological and chemical warfare. By the end of the Second World War, a new group of chemical agents had been developed in Germany, namely, the nerve gases, the characteristics of which he then described, pointing out the high toxicity of some of these in both the liquid and vapour phases. A satisfactorily sensitive test for detection has been developed, and civil defence services will be provided with a vapour detcctor kit capable of identifying the vapour of either mustard gas or the nerve gases in the required concentrations. The technical reconnaissance officer will be responsible for gas detection in the field and for advice on any measures required to deal with the situation resulting from an attack with chemical agents. He must in addition always be on the lookout for unusual effects, for it cannot be assumed that new and even more toxic agents will not be discovered. Systematic study of the behaviour of war gases in cities would be of the greatest importance, for there is no practical experience of their use in such circumstances, The role of the trained chemist in collecting such data would be of great value to the 
scientists at regional and government headquarters, and would also be of value to the Armed Forces.

The effectiveness of biological warfare, Prof. Rydon said, is still unknown; but he thought the wild stories about a single bomb causing a widespread epidemic could be dismissed as fantastic. Comparatively little is yet known about the precise conditions required for initiating an epidemic; but it is known that to cause one deliberately at a selected time would be very difficult. Advances in the development of new drugs and antibiotics also reduce the possible choice of agents which might, even theoretically, be expected to achieve such an object. The standard of hygiene in modern organized communities is another factor which reduces the chances of epidemics being successfully initiated by attack from the air. Sabotage might perhaps remain a possibility; but this method would be localized in its effect and more amenable to control. If the epidemic idea be dismissed, biological warfare may be regarded as an exaggerated form of chemical warfare with agents having a toxicity greater than any of the war gases by a factor of tens; but against this the chances of people receiving an effective dose are probably reduced by a factor of a similar order. Biological warfare is a possibility with which cjvil defence must be prepared to deal ; but there are still many problems connected with the choice of suitable agents and finding effective methods of using them, so that the chance of its success as a method of waging war may still be problematical. Whereas the potentialities of chemical warfare can be evaluated with fair accuracy, biological warfare is still an untried weapon.

In preparing to meet such threats, the services of trained chemists would be invaluable, and Prof. Rydon hoped that as a result of the meeting there would be a good response from chemists. The chemist could adequately perform many of the tasks connected with atomic and biological warfare as well as those in the chemical field, for his training puts him in a category intermediate between the physicist and the biologist. He hoped no one would withhold his services under the impression that civil defence is a purely passive function. The application of scientific advice could go a long way towards defeating an enemy's objective by minimizing the effects of his weapons, and this could at times be as important as the active operations of offensive warfare.

Sir John Hodsoll, director-general of training in the Civil Defence Department of the Home Office, said he could sympathize with what had been said about the Second World War, for some gas identification officers had undoubtedly been put in a difficult position; but it was hoped to benefit from the lessons which had been learnt. As to background, it was not intended that technical reconnaissance officers should take full basic training, and if this had occurred in some cases it must have been due to misunderstanding. In peace-time, scientists can make a valuable contribution by local studies designed to define the tactical problems resulting from different forms of attack.

In the civil defence organization there would be a chief reconnaissance officer at all control and subcontrol centres, and he or his deputy would always be a technical reconnaissance officer, so that the controller would always have advice immediately available on the technical aspects of any problem. As regards recruitment, it is recognized that difficulties may have to be smoothed out in some cases; but it is in the local division that the technical reconnaissance officer is needed, so he must be part of the local organization. If success in any future war is to be achieved, civil defence services must be organized and trained now; for if the civilian population should give way a war would be lost even though the main military forces with all their equipment and resources still remained virtually intact. The real way to achieve this object is to see that knowledge of the right kind is available to all who should have it, and in this task the scientist can perform a most valuable work in creating the right attitude of mind among the general public.

The meeting was then thrown open for questions and general discussion, and many of the speakers elaborated the points made by the chairman in his opening address, particularly regarding the status of technical reconnaissance officers and their method of recruitment. Several speakers thought recruitment could be more effectively dealt with by making more use of the professional institutes. One speaker said that these particular difficulties are not universal, for, during the Second World War and again in the new arrangements, his relationship with his local authority was most satisfactory. Much emphasis was laid on the importance of giving scientific people the full technical details in all information furnished to them. A suggestion was made that an attack with biological agents after a heavy attack with high explosive might well produce an epidemic, since the standard of hygiene would be sub-normal and sanitation services would be disorganized. A question was asked about the arrangements for liaison with medical services, as some members feared that in certain circumstances difficulties were likely to arise. Another suggestion was made that radiotherapists, who had not apparently been considered for reconnaissance work, could be of value in the assessment of radiological hazards.

Sir Charles Ellis, senior scientific adviser in the London region, stressed the importance of the operational research approach to the type of problems which the technical reconnaissance officer would have to study. People trained to observe phenomena closely and to collate and interpret the data obtained could contribute a great deal to civil defence, and, whatever this type of work be called, such an officer should in effect be an operational research worker.

Dr. E. T. Paris, scientific adviser to the Home Office, in his summing up of the proceedings before answering some of the questions, said that the Home Office was much indebted to the three Institutes for organizing the meeting. Note would be taken of the points which had been made, and he was sure the discussion would be of value in further consideration of the problems involved. The need for scientists in civil defence had been clearly shown, as was confirmed by the discussion, since acceptance of the principle was implicit in the remarks of all speakers, however critical they might be on specific details.

The status of scientists in civil defence, Dr. Paris said, appears to be causing much anxjety. The position is that there are two distinct levels at which scientists are employed. The regional scientific advisers would assist the regional commissioners on all appropriate matters in each region, and in addition would have laboratory facilities and trained staffs for dealing with samples received from local authorities. On technical matters, they would work in direct collaboration with the Home Office and the 
appropriate Ministry of Supply research establishments. At the next level, the technical reconnaissance officers are in the headquarters section of the local division so that, as Sir John Hodsoll had explained, they are part of the local authority's organization and must in the long run be recruited through that machinery, though he would take note of the diffculties mentioned. The plea for full technical information was one with which every scientist would sympathize; though there is no secrecy in civil defence as such, it has to be recognized that information of a secret nature is used in the Home Office in the study of civil defence problems, so that it is not possible to pass on some kinds of information. From his own experience, he agreed with the principle that secret information should be given only to those who must have it in order to carry out their duties. $\mathrm{He}$ did not think there is any greater likelihood of an epidemic resulting from biological warfare attack after an attack with high explosives than in other circumstances. In any event it is necessary to guard against the tendency to conjure up complicated defence problems by piling one form of attack on another. A very great effort is required to deliver a modern attack on an effective scale, and any complication of the kind suggested must reduce the effectiveness of the first attack without greatly increasing the chance of the second attack being more effective than if it had been delivered alone on the appropriate scale.

Suggestions had been made about the possibility of the atomic bomb being 'played down' unjustifiably, and in particular a question was asked how this could be reconciled with the casualty figures published after the visit of the British Mission to Japan. There was no intention of minimizing the potentialities of the bomb; but what had been attempted was to show how the number of resultant casualties might vary in different circumstances. For example, if it was assumed that an unwarned attack on a city with the population all exposed in the open would result in, say, 50,000 casualties, then it could be shown that if everybody was in houses of an assumed standard of construction the casualties would be reduced to 30,000 under the same attack; and again, if they were all in special shelters of a specified standard of protection, the casualties would fall to 10,000 .

In conclusion, Dr. Paris said the discussion had served a most useful purpose in providing evidence of the kind of difficulties that might arise in setting up the reconnaissance service, and of the lines on which interested scientists were thinking on these matters. Since the meeting, he has agreed to consider the problem in consultation with the three Institutes which organized the discussion.

J. W. Martin

\section{THE ALEMBIC CLUB}

\section{By Prof. JAMES KENDALL, F.R.S.}

$\mathrm{O}^{\mathrm{N}}$ October 29, 1889, the five non-professorial members of the teaching staff of the Chemistry Department in the University of Edinburgh formed themselves, under the title of "The Alembic Club", into "an unassuming body which was destined later to play a useful part in bringing historical material connected with chemistry within the reach of interested readers". In order of seniority, the original members of the Club were:
1. John Gibson. The originator, with Prof. Crum Brown, of the famous Crum Brown-Gibson rule for determining the position of radicals entering a substituted benzene nucleus. Professor of chemistry in the Heriot-Watt College, Edinburgh, 1892. Died in 1914 .

2. Leonard Dobbin. Distinguished for his research work in the history of chemistry and for his translations of Ladenburg's "Lectures on the History of the Development of Chemistry since the time of Lavoisier" (1900) and Scheele's "Collected Papers" (from Swedish and German originals, 1931). He was lecturer in chemistry in the University of Edinburgh, 1914 ; reader, 1920. Dr. Dobbin died in March 1952 in his ninety-fourth year. For seventy-one years he was a Fellow of the Royal Society of Edinburgh (Member of Council 1904-7 and 1913-16, Curator 1934-39, Vice-president 1939-42) and for more than sixty years a Fellow of the Chemical Society and the Society of Chemical Industry. Secretary of the Alembic Club from its inception to 1946 , he was its guiding spirit throughout that long period.

3. Hugh Marshall. Discoverer of the persulphates ; elected a Fellow of the Royal Society in 1904. After holding a lectureship in crystallography in the University of Edinburgh, he was appointed to the chair of chemistry in University College, Dundee, in 1908 ; he died in 1913.

4. James Walker. For many years the leading physical chemist of Great Britain. Professor of chemistry in University College, Dundee, 1894-1908, and in the University of Edinburgh, 1908-28. He was awarded the Davy Medal of the Royal Society in 1926, and the Gunning Victoria Jubilee Prize of the Royal Society of Edinburgh in 1932. President of the Chemical Society, 1921-23. Knighted in 1921 and died in 1935.

5. Alexander Smith. Famous for his research work on the allotropic forms of sulphur and for his series of text-books on inorganic and physical chemistry. Professor of chemistry in Wabash College, Indiana, 1890-94, in the University of Chicago 18941911, and head of the department of chemistry in Columbia University, New York, 1911-20. President of the American Chemical Society, 1911. Died in 1922 .

Members elected afterwards were :

6. Ralph Stockman (1891). Professor of materia medica in the University of Glasgow, 1897-1936. Elected a Fellow of the Royal Society in 1889. Vice-President of the Royal Society of Edinburgh, 1939 42. Died in 1946 .

7. James Kendall (1929). Professor of chemistry in Columbia University, 1914-26, in New York University, 1926-28, and in the University of Edinburgh, 1928 to date. Secretary of the Alembic Club since 1946.

8. Irvine Masson (1932). Professor of chemistry, University of Durham, 1924--38 ; vice-chancellor of the University of Sheffield, 1938-52. Knighted in 1950.

9. Oswald James Walker (1937). Formerly lecturer in chemistry, University College, London, now on the staff of Imperial Chemical Industries, Ltd. (Plastics Division), Welwyn Garden City.

At a very early stage in the existence of the Club, the important resolve was taken to publish some of the less easily accessible chemical classics in convenient form, as simple reprints (if in English) or as translations (if in a foreign language). It was fitting that the first of these "Alembic Club Reprints" should present in 1893 Joseph Black's world- 